\title{
EL ARBITRIO JUDICIAL EN LA BAJA JUSTICIA DEL DERECHO CRIMINAL EN EL SIGLO XIX. EL CASO DEL ESTADO DE MÉXICO
}

\begin{abstract}
SUMARIO: I. Introducción. II. Algunas de las obras jurisprudenciales representativas del derecho castellano-indiano. III. El arbitrio judicial en México: el caso del Estado de México. IV. La administración de justicia criminal en la baja justicia. V. Comentarios finales. VI. Bibliografía.
\end{abstract}

Mario A. TÉLLEZ G.*

\section{INTRODUCCIÓN}

Este trabajo tiene como objetivo abordar brevemente, por un lado, la situación de la dogmática penal en el México del siglo XIX en torno al arbitrio judicial y, por la otra, contrastarla con la realidad del foro del Estado de México en el ámbito criminal de la llamada baja justicia, y más tarde conocida como primera instancia. Y aunque no es interés central en este trabajo, cuando sea posible, también recogeremos las resoluciones que se dieron en apelación o suplicación para apreciar el ciclo completo de la administración de justicia.

Fue precisamente en el lejano y celebrado 1992, durante el Quinto Centenario del Encuentro de Dos Mundos, cuando Víctor Tau publicó su extenso e interesante trabajo, Casuismo y sistema ${ }^{1}$ para intentar, a través de estos

* Profesor investigador. Universidad Autónoma Metropolitana. Unidad Cuajimalpa.

1 Tau Anzoátegui, Víctor, Casuismo y sistema. Indagación histórica sobre el espíritu del derecho indiano, Buenos Aires, Instituto de Investigaciones de Historia del Derecho, 1992, pp. 30 y 31. No es el espacio para ahondar sobre este importante texto, sin embargo, por lo relevante que resulta para nuestro trabajo, vale la pena transcribir las siguientes ideas de Tau, apoyado a su vez en lo expuesto por Helmut Coing: "Los sistemáticos consideran al Derecho como un conjunto estructurado de normas jurídicas, racionalmente elaborado que, además de orden externo, tiene una conexión interna conceptual y encierra en sí mismo todas las soluciones a los posibles problemas que se plantean en la vida social... Los casuistas en 
dos conceptos, "ir en busca de creencias e ideas que, palpitando por debajo de la legislación, la jurisprudencia o la actividad judicial, dan sustento y confieren peculiaridad al orden jurídico hispano-indiano y estimulan su transformación". ${ }^{2}$ Buscó explicar la transición del "casuismo" colonial a la forma sistemática construida por el racionalismo ilustrado de finales del siglo XVIII, y que entroncó en algún momento con el positivismo jurídico para proyectarse, aunque con muchos y variados problemas, hacia el siglo XIX en toda la América hispánica. Por supuesto que el calado y ambición intelectual de este trabajo fue sobresaliente, y en parte orientador de lo que aquí se escribe; sin embargo, creemos que a pesar de sus destacados logros es necesario ahondar más en la aplicación de esta figura jurídica en el foro particular del Estado de México, y que desde nuestro punto de vista es mucho más importante de lo que hasta ahora se ha estudiado. Por cierto, y dicho sólo de forma incidental, no lo hemos apreciado en la historiografía.

También es cierto que la baja justicia en el Estado de México para el siglo XIX fue objeto de nuestro interés hace ya varios años. ${ }^{3}$ Sin embargo, en aquella ocasión nuestra atención estuvo centrada particularmente en la cuantificación y, por lo tanto, el arbitrio judicial no fue una institución a la que se le dio la atención debida. Fueron los años de reflexión sobre el tema los que nos permitieron entender que no lo habíamos ponderado lo suficiente.

Pero vayamos con detenimiento, ¿en qué consistía o qué era la institución del arbitrio judicial? El propio Víctor Tau lo define así, era la

exteriorización de la vigorosa concepción casuista, en cuanto delegaba en el juez o en el ministro la facultad de decidir determinada situación según la

cambio, sostienen que el Derecho, aunque apoyado en normas, sólo se realiza en la decisión de los casos, tal como se van presentando, de modo que la búsqueda de la solución reposa en la percepción del problema concreto, examinando las circunstancias de tiempo, lugar y calidad de las personas. De ahí que hagan residir la justicia en el adecuado desenlace de cada situación y no en la mera aplicación de un cerrado sistema normativo".

2 Reconocemos que hay otras explicaciones más nuevas y complejas sobre los cambios sucedidos entre el siglo XVIII y XIX para el caso español, y más particularmente para la Nueva España, pero preferimos adscribirnos a la postura de Tau por referirse de forma central al arbitrio judicial, y ser, desde nuestro punto de vista, más clarificadora. Véase de forma indicativa Garriga, Carlos, "Continuidad y cambio del orden jurídico", id. (coord.), Historia y Constitución. Trayectos del constitucionalismo hispano, México, Centro de Investigación y Docencia Económicas-El Colegio de México-El Colegio de Michoacán-Escuela Libre de Derecho-Grupo Hicoes-Universidad Autónoma Metropolitana, 2010, pp. 59-106.

3 Téllez G., Mario A., La justicia criminal en el Valle de Toluca 1800-1829, Estado de México, El Colegio Mexiquense, 2001. 
apreciación que él realizara de las circunstancias de las cosas y de las personas. Era, pues, una atribución creadora de Derecho en determinadas ocasiones, ya otorgada por ley, doctrina o costumbre ya dada de modo implícito [...] concedía al juez amplias facultades para adecuar las penas a los casos concretos que debía resolver. ${ }^{4}$

¿Y qué se entendía por la "concepción casuista" o, mejor dicho, por el casuismo jurídico? Era nada menos que la forma de vivir el derecho, y su construcción llevó cientos de años, desde el siglo XII, con la revigorización del derecho justinianeo, hasta muy entrado el siglo XIX, donde el propio derecho, de acuerdo con Tau, "no podía exponerse por medio de una regla general, ni con uniformidad abarcadora de muchos reinos o provincias, ni con la pretensión de ser invariable en el tiempo. El caso, el lugar y el tiempo eran centros de preocupación de ministros y juristas". ${ }^{5}$ Podríamos decir, junto con Tau, que el arbitrio judicial fue una de las partes fundamentales, si no es que probablemente una de las más relevantes del derecho de ese largo periodo, porque le dio su sello distintivo, al menos en la vida del foro, y con marcada importancia en el ámbito criminal hasta principios del XIX, cuando finalmente se dio un cambio hacia la codificación jurídica, hacia el derecho sistemático, donde se pensó ilusamente que podía acabarse con el arbitrio judicial.

No obstante el cambio de mentalidad, la realidad del México independiente no se modificó, porque no pudo concretarse la promulgación de los códigos — no sólo los penales-, y ello derivó que se siguiera administrando justicia de la misma forma que siglos atrás. La guerras intestinas que se dieron a lo largo del siglo, así como los cambios de régimen, prolongaron esta situación hasta muy entrados los años ochenta. Para los últimos lustros, no es difícil encontrar las dudas que enfrentaron los abogados y los juzgadores para aplicar la vieja dogmática o la nueva, o incluso, hubo quienes tratando de evadirla aplicaron las dos en una peculiar convivencia jurídica, pero, en todo caso, resolvieron el conflicto al emitir una sentencia.

\section{Algunas DE LAS OBRAS JURISPRUdENCIALES REPRESENTATIVAS DEL DERECHO CASTELLANO-INDIANO}

De acuerdo a la visión de Víctor Tau, hay tres obras representativas que muestran de forma importante la relevancia del arbitrio judicial para América

\footnotetext{
4 Tau Anzoátegui, Víctor, op. cit., pp. 534 y 535.

5 Ibidem, pp. 81 y 82 .
} 
Latina y que fueron muy populares en los juristas y que tuvieron diversas ediciones: Jerónimo Castillo de Bobadilla, Política para corregidores y señores de vasallos en tiempos de paz y guerra, Imprenta Real de la Gazeta, 1775, vols. II y III; Juan de Solórzano Pereira, Politica indiana, Madrid, Matheo Sacristán, 1736; y Juan de Hevia Bolaños, Curia Philípica, Madrid, Ramón Ruiz, 1797.6

Por cuanto a las obras que influyeron en el derecho penal mexicano del siglo XIX, amén de las que menciona Tau, también pueden citarse Las Siete Partidas, en primer lugar, - a las que por cierto Tau no hace mención, lo que nos parece muy extraño por su recurrencia en el foro mexicano y seguramente en todo el ámbito latinoamericano-; Joaquín Escriche, Diccionario razonado de legislación civil, penal, comercial y forense, México, UNAM, 1996; y a José Marcos Gutiérrez, Práctica forense criminal, vols. I, México, 1850; y vol. II y III, México, Tipografía de R. Rafael, 1851. Las tres obras contaron con múltiples ediciones, aunque Las Siete Partidas, por su relevancia, seguramente alcanzaron un mayor número. Por supuesto que hubo muchas otras que circularon en el foro mexicano, pero nosotros referimos éstas a partir de la experiencia que hemos tenido en la revisión de expedientes penales en la baja justicia o primera instancia en el Estado de México, y son las que de forma reiterada encontramos mencionadas.

Indudablemente que en la transición al nuevo régimen, con la aparición de la codificación racionalista en el pensamiento jurídico de la época, se intentó - sobre todo en el ámbito del derecho criminal — acabar con el uso y abuso del arbitrio, institución que se pensaba como uno de los peores lastres de esa forma de concebir el derecho. Aunque del otro lado, también había la intención de restarle poder a los jueces, en su condición de creadores del derecho, para que la división de poderes, en la concepción racionalista de finales del siglo XVIII, pudiera incorporarse al andamiaje de los nuevos Estados nacionales. Es decir, al menos en la teoría, en el nuevo Estado nacional los legisladores estaban dedicados a crear las leyes y los juzgadores a aplicarlas; cada uno en el ámbito de su competencia.

Es un hecho incontrovertible que uno de los objetivos más caros de la codificación racionalista en Occidente, cristalizada finalmente con la publica-

6 El repertorio bibliográfico que los juristas podían consultar era amplísimo, Tau sólo refiere a los que son más influyentes desde su punto de vista. Sólo de manera ilustrativa, véase a Tomás y Valiente, Francisco, El derecho penal de la monarquía absoluta (siglos XVI, XVII y XVIII), Madrid, Tecnos, 1992; al propio Tau Anzoátegui, Víctor, op. cit., y a Ortego, Pedro, "De la literatura jurídica al código penal. Causas y circunstancias en el derecho histórico español", Boletim da Facultade de Direito de Coimbra, núm. 83, 2007, pp. 241-302. 
ción del Código Civil napoleónico de 1804, después de décadas de largas e intensas discusiones, fue la "transición entre la herencia colonial y las ideas modernas" en sentido general, y su larga adaptación a lo largo de los distintos países latinoamericanos que se formaron en ese periodo, herederos de la fuerte tradición centenaria del derecho castellano-indiano, en lo particular. ${ }^{7}$ Se pensó que con ello se terminaría definitivamente con la posibilidad de interpretar la ley. ${ }^{8}$

También puede decirse que buena parte de la transición, a la que se refiere Tau, significa que con la aplicación de la racionalidad al derecho, al juez penal - instalado en la más perfecta lógica aristotélica-, a partir de la premisa mayor y ubicando en la legislación — promulgada por el Poder Legislativo - la ley o leyes susceptibles de aplicarse al caso concreto o premisa menor, sólo le quedaba verificar la exactitud y ensamblaje puntual de ambas, para concluir de inmediato cuáles serían las consecuencias jurídicas para quienes estaban involucrados en un litigio en particular; consecuencias que también estaban incluidas en la ley.

Por supuesto que la sustitución del arbitrio judicial no fue una tarea sencilla, se trataba de una institución forjada a lo largo de varios siglos. Apareció claramente desde Las Siete Partidas ( $L S P$ ) 7, 31, 8: "Qué cosas deben catar los jueces ante que manden dar las penas, et porqué razones las pueden crescer, ó menguar ó toller", las cuales, muy probablemente fueron el texto jurídico medieval más influyente en la América Hispánica. De allí en adelante se fue robusteciendo en la doctrina y en la vida del foro hasta la segunda mitad del siglo XVIII, cuando ya era severamente cuestionado. No obstante esta lucha se prolongó para el caso mexicano y otras regiones hasta la mitad del siguiente siglo.

Y sin duda que fue el marqués de Beccaria quien pudo acrisolar en 1764, en su famoso Tratado de los delitos y de las penas, las necesidades de cambio que dominaba ya al derecho criminal europeo. Entre sus principales preocupaciones no se encontraba tanto el arbitrio judicial — que quedaba trascendido con su propuesta - sino el nuevo estadio que debía alcanzarse, y lo expresó de esta forma:

7 Ramos Núñez, Carlos, El Código napoleónico y su recepción en América Latina, Lima, Pontificia Universidad Católica del Perú, 1997, p. 29.

8 Tau Anzoátegui, Víctor, op. cit., p. 534. Este autor señala acertadamente que el uso del arbitrio no se limitó en Indias a la materia criminal, de ahí el nombre compuesto de arbitrio judicial, sino que la facultad de decidir por parte de la autoridad en aquellos asuntos no regulados por ninguna disposición estaba extendida a todos los ámbitos de la sociedad. 
En todo delito debe hacerse por el juez un silogismo perfecto. Póngase como mayor la ley general; por menor la acción, conforme ó no con la ley, de que se inferirá por consecuencia la libertad ó la pena. Cuando el juez por fuerza ó voluntad quiere hacer más de un silogismo, se abre la puerta a la incertidumbre $[\ldots]$

¿Cuántas veces vemos los mismos delitos diversamente castigados por los mismos tribunales en diversos tiempos, por haber consultado, no la constante y fija voz de la ley, sino la errante inestabilidad de las interpretaciones?

Un desorden que nace de la rigurosa y literal observancia de una ley penal, no puede compararse con los desórdenes que nacen de la interpretación. ${ }^{9}$

Por su parte, Manuel de Lardizábal en 1782, representante muy destacado del pensamiento ilustrado español de esa época y seguidor en buena medida del pensamiento de Beccaria, lo expresaba así:

Toda la facultad de los jueces debe reducirse, únicamente, a examinar si el acusado ha contravenido o no la ley para absolverle o condenarle en la pena señalada por ella. Si se dejase a su arbitrio [del juez] el imponer penas, el derogarlas o alterarlas, se causarían innumerables males a la sociedad. La suerte de los ciudadanos sería siempre incierta, su vida, su honra, sus bienes quedarían expuestos al capricho, a la malicia, a la ignorancia y a todas las pasiones que pueden dominar a un hombre. Si no hay leyes fijas, o las que hay son oscuras, o están enteramente sin uso, es preciso caer en el inconveniente del arbitrio judicial, si la potestad legislativa no cura a este daño haciendo leyes, aclarando las oscuras y subrogando otras nuevas en lugar de las anticuadas. ${ }^{10}$

Detrás de la idea de Beccaria, a la que se sumó Lardizábal y otros muchos pensadores más, y del enorme revuelo intelectual que causó en Europa, existía la esperanza que después de siglos de avatares en el foro se alcanzaría la ansiada justicia. Es decir, el juzgador, por virtud del abuso del arbitrio judicial que había hecho desde siglos atrás, dejaría de ser creador del derecho, caso por caso, para convertirse definitivamente mediante la utilización de los códigos sólo en un "simple" aplicador del derecho.

Esta última pretensión, que por su brevedad y simpleza fue aceptada como una verdad incuestionable por los juristas de esa época, no era tal. Es

9 Beccaria, Cesare, Tratado de los delitos y de las penas, 9a. ed., México, Porrúa, 1999, pp. 15-17.

10 Véase el extenso texto de Ortego, Pedro, op. cit., en el que explica la transición del derecho de antiguo régimen a la modernidad en el derecho español, a través de la institución del arbitrio judicial y su sustitución por el principio de legalidad. 
decir, sí fue un anhelo, pero de la revisión de la dogmática de esos años puede apreciarse que en realidad lo que se logró fue acotar en gran medida el margen del arbitrio del juzgador, pero en última instancia, el proceso lógico de elegir unas leyes en particular o unos artículos del código en específico, y luego elegir la serie de consecuencias aplicables que esos mismos códigos daban significaba, en esencia, que el juzgador siguiera usando su arbitrio, aunque de forma mucho más limitada. Sumado al hecho de que los códigos no podrían agotar todas las posibilidades de los hechos y actos jurídicos. Por supuesto que esta idea no es novedosa, pero hay pocos textos para el caso mexicano, entendido en un amplio sentido, que hayan contrastado la dogmática de la época con la realidad de los tribunales. ${ }^{11}$

\section{El arbitrio Judicial en MÉXico: el CASO DEl Estado De MéXico}

Por supuesto que en el caso novohispano primero, y después en el mexicano, la situación que imperó en el derecho criminal fue de continuidad y el arbitrio judicial, por consecuencia, fue una de las figuras jurídicas más destacadas y que permanecieron en el tiempo. ${ }^{12}$

Como ya se comentó arriba, en México, al término del periodo colonial, el arbitrio judicial no sufrió ninguna modificación en su aplicación y sobrevivió más allá de los años setenta, momento en el que finalmente pudieron promulgarse los primeros códigos. Las grandes discusiones sobre la división de poderes y otros dogmas políticos relevantes no permearon en la baja justicia, a donde las cosas, mutatis mutandis, siguieron funcionando igual. La situación que prevaleció en el foro desde principios del siglo hasta los años ochenta puede ponderarse a través de los comentarios de algunos de los textos y autores de esos años.

Por supuesto que las críticas que se le habían hecho a esta figura desde finales del siglo XVIII continuaron posteriormente.

11 Lardizábal y Uribe, Manuel de, Discurso sobre las penas (1782), edición de Andrés Moreno Mengíbar, Cádiz, Universidad de Cádiz, 2001, p. 145.

12 En otra oportunidad se ha discutido sobre la importancia de esta figura. Véase "el arbitrio judicial". Téllez G., Mario A., La justicia criminal..., op. cit., pp. 200-211. Parece que algo similar sucedió en los primeros años independientes en la Provincia de Buenos Aires. Yangilevich, Melina, "Administración de justicia, derecho, gobierno y prácticas judiciales en la construcción estatal (Buenos Aires, 1821-1886)", en Caselli, Elisa (coord.), Justicias, agentes y jurisdicciones. De la monarquía hispánica a los Estados nacionales (España y América), Madrid, FCE, 2016, p. 400. 
Veamos algunos ejemplos. Una de las obras de mayor influencia en el foro del Estado de México, como el Diccionario razonado de legislación, en la voz "pena", al final del penúltimo párrafo repetía, casi textualmente, aunque en una versión modernizada, la misma idea que siglos antes habían avanzado $L S P$ sobre el arbitrio: "Con cuidadosa atención á estos principios puede el juez aumentar, disminuir ó quitar las penas, según estime justo", y que no es otra cosa que la referencia expresa a $\operatorname{LSP} 7,31,8$ : este texto es uno de los sustentos jurídicos más relevantes y de mayor longevidad del arbitrio judicial, citado de forma reiterada, alusiva o expresa, en buena parte de los expedientes criminales del centro de México para el siglo XIX, que hemos revisado a lo largo de los años. Sin embargo, extraña que no se le dedicara un espacio particular para explicarlo, dado lo extendido de su aplicación. Una posible explicación, sólo por especular, podría ser que como se trataba de una figura jurídica medular de la forma de entender la administración de justicia, no se le diera una atención especial. Además, y eso seguramente abonó mucho para las primeras décadas del siglo XIX, fue muy criticada por los estudiosos del derecho de esa época, porque se oponía precisamente a uno de los supuestos fundamentales de la codificación, acotar las posibilidades de interpretación del juzgador.

Por ello, no extraña que la Memoria ... del Gobierno del Estado de México de 1831, en la que se reconocía la realidad de la administración de justicia, apuntara claramente en sentido crítico:

Pero en lo que más se nota esta falta de legislación es en la parte criminal, leyes atroces y bárbaras, desnudas de toda filosofía, dictadas sin ningún conocimiento del corazón humano y con la mira de reprimir las brutales costumbres de la edad media [...] Ya por estos motivos, y bien porque muchas penas de esas leyes son inaplicables físicamente [...] se puede decir sin exageración que se carece de todo derecho escrito, pues aún las pocas leyes penales que no serían tan disconformes con las instituciones, no son fáciles de ejecutar sin grave riesgo de faltarse á la proporción debida entre la pena y el delito [...] De aquí se sigue necesariamente, que sin otro regulador de las acciones públicas que el arbitrio de los jueces, la vida, el honor, la fama y cuanto tiene de precioso el ciudadano, se halla en el día á merced y discreción del buen ó mal humor de estos funcionarios: de su ignorancia y preocupaciones y de todas las disposiciones morales que constituyen la probidad, el talento y la instrucción. ${ }^{13}$

13 Memoria en que el Gobierno del Estado Libre de México, da cuenta al Congreso Constitucional, de todos los ramos que han sido a su cargo en el año económico, corrido 
Sin embargo, la falta de acuerdos básicos por parte de los bandos en pugna facilitaron su permanencia, y que todo el aparato de justicia siguiera funcionando prácticamente en los mismos términos que durante el régimen anterior. Hubo muy poco espacio para legislar sobre otras materias que no estuvieran directamente relacionadas con el ámbito de la política y de la definición ideológica del gobierno en turno.

Otras muchas otras voces se manifestaron también en torno al arbitrio judicial. Precisamente el abogado Joaquín Martínez Íñigo de Rojas, a mediados de siglo XIX, en la edición mexicanizada de la importante y difundida Práctica criminal de José Marcos Gutiérrez, hacía el siguiente comentario:

Después de haber explicado el autor, con el tino y maestría propios de su vasta erudición [se refería a la Práctica criminal de José Marcos Gutiérrez], los diversos delitos que se conocen en el foro, y las penas á que se encuentran afectos, solo resta manifestar que como desde que la nación mejicana se hizo independiente del gobierno político de la España, no ha llegado á sancionarse algún código penal, se han introducido en la práctica muchas innovaciones, cuyo resultado ha sido el colocar á los jueces en la difícil y peligrosa posición de aplicar penas arbitrarias por falta de disposiciones legales; en efecto, algunas de las antiguas leyes españolas han sido expresamente derogadas, otras han caído en desuso por suponerlas contrarias al sistema libre que nos rige, y no habiendo sustituidas con otras, como parece debían haber hecho nuestros legisladores, ha sido preciso que los jueces, al tiempo de fallar en los procesos, hagan uso de penas arbitrarias; por eso es que casi todas las sentencias, así de primera como de segunda instancia, se encuentran apoyadas en la ley 8a., tít. 31, P. 7a. [referida arriba y fundamento del arbitrio judicial], y por eso también se ha generalizado una disposición que debiera explicarse en ciertos y determinados casos. Mas ya que por fatalidad no existe entre nosotros algún código penal, ya que nuestra legislación que se ve tan complicada que forma un positivo laberinto, impútese á esto y no á la supuesta omisión de nuestros jueces, la impunidad de los delitos: en efecto, cualquiera que conozca nuestro foro criminal, que haya visto el despacho en los procesos y las dificultades que se tienen que superar, se convencerá hasta la evidencia de que los jueces no tienen medios de acción bastante para llevar al cabo sus providencias y conseguir el descubrimiento de los delitos para castigarlos. [subrayado nuestro] ${ }^{14}$

desde 16 de octubre de 1829, hasta 15 de igual mes de 1830. Presentada el día 2 de marzo de 1831, s. p. i., pp. 65-68.

14 Gutiérrez, José Marcos, “Apéndice al tomo tercero de la práctica criminal”, Práctica forense criminal, México, Imprenta de Juan R. Navarro, 1850, t. III. 
Está claro que la intención del abogado Joaquín Martínez era explicar la ineficacia de los jueces de la época por falta de códigos o leyes para hacer su trabajo, pero sus observaciones permiten también puntualizar y conjeturar un poco más sobre el contexto histórico del arbitrio judicial. No es difícil reconocer que cuando Joaquín Martínez habla de las "penas arbitrarias" se está refiriendo en parte al uso abusivo del arbitrio judicial. El problema, o mejor dicho, su inexactitud consiste en mencionar que los jueces tuvieron que aplicar las "penas arbitrarias" por el cambio de régimen y la inexistencia del código penal, como si se tratara de una práctica novedosa y no de una que se remontaba siglos atrás. Él mismo lo confirma al citar precisamente a $\operatorname{LSP} 7,31,8$.

Por otra parte, algo que sí podría ser muy revelador, y tendría que comprobarse en alguna investigación ulterior, derivado de sus comentarios, es saber si el cambio de régimen y la ausencia de un código penal que no terminaba de promulgarse exacerbó el uso del arbitrio judicial, o más bien eran las transformaciones lógicas de una institución que había sido utilizada en el muy largo plazo. Cuando se estudien sistemáticamente expedientes penales de la colonia y del México del siglo XIX, por periodos prolongados, podría comprobarse esta hipótesis. Y por cuanto al comentario que hizo sobre la falta de "medios de acción" que tenían los jueces, si por ello entendía la debilidad institucional del Estado mexicano para hacer valer el imperio de la ley, nos parece que puso el dedo en la llaga, efectivamente esa debilidad fue toral para el mundo de la administración de justicia de esos años.

El análisis de varios cientos de causas penales que se hizo para el Valle de Toluca (1800-1829) ${ }^{15}$ se puede mencionar como un ejemplo incipiente de futuras investigaciones; si bien limitado en su temporalidad e ilustrativo en su contenido, todavía insuficiente para aclarar esa hipótesis. Tendrán que hacerse estudios más ambiciosos. No obstante, de todos los expedientes criminales que se estudiaron, resulta muy elocuente que en ninguno se aplicó la pena ordinaria. Frente a los homicidios, robos, lesiones, "incontinencias" (como parte de los delitos sexuales) y demás conductas delictivas registradas a lo largo de las tres décadas, los jueces ordinarios prácticamente siempre sancionaron conforme a su arbitrio, aplicando penas extraordinarias - en su gran mayoría atemperadas - . Es decir, de haber sido consecuentes con lo establecido por la doctrina y la legislación vigentes, muchos reos habría sido condenados a sufrir la pena de muerte a través de distintos e inhumanos medios. Más aún, en el único caso encontrado en ese universo

15 Téllez G., Mario A., La justicia criminal..., op. cit. 
documental, en el que un juez intentó imponer una pena de azotes, que era también una pena arbitraria, la Audiencia la rechazó en segunda instancia para cambiarla por prisión. ${ }^{16}$ Es decir, en esta investigación se confirmó que efectivamente el arbitrio judicial sirvió para atenuar la severidad del derecho criminal vigente. Sin embargo, esta circunstancia coincide exactamente con lo apuntado por Víctor Tau para el mundo colonial, ${ }^{17} \mathrm{el}$ arbitrio judicial como "dulcificador" de la dureza del derecho criminal. Por supuesto que el arbitrio también pudo usarse para perjudicar a alguien, difícilmente para aumentar la pena, dado que el derecho era muy severo, pero sí para aumentar la prisión, la multa o empeorar el destino del reo. Sin embargo, son escasos los expedientes que hemos localizado en este sentido, los cuales simplemente confirmarían la regla del uso benevolente del arbitrio.

Por otra parte, la discusión sobre la necesidad de codificar el derecho estuvo presente en la Nueva España desde 1812 con la Constitución gaditana, y se prolongó en el México independiente por varias décadas, pero como en otras tantas circunstancias, la lucha política impidió que se consolidara hasta los años setenta, cuando finalmente vieron la luz los primeros códigos civil y penal del país en 1870 y 1871 , respectivamente. Poco después los estados harían lo propio; aunque la gran mayoría de las legislaturas locales los copiaron y tomaron como suyos. ${ }^{18}$

Finalmente, hay que llamar la atención sobre el papel determinante que jugaron los abogados en el mundo de la administración de justicia y que todavía no ha sido valorado en su verdadera magnitud. De momento está claro que fueron, en su calidad de "asesores letrados" y de representantes de las partes en controversia o de juzgadores principalmente, los responsables de la continuidad del derecho colonial más allá del cambio político y de régimen de 1821. Es cierto que para los primeros lustros tampoco podían actuar de forma distinta. Estaban educados para respetar el derecho que otros abogados, sus maestros, les habían enseñado, y frente a la falta de un nuevo marco jurídico que descansaba sobre ideas distintas, no les quedaba

16 Ibidem, pp. 200-211.

17 Ibidem, pp. 201 y 202. Víctor Tau cita a Jaime Eyzaguirre y a Ricardo Zorraquín como autores que reconocen al arbitrio judicial como factor de templanza en el rigor de las penas. Tau Anzoátegui, Víctor, op. cit., p. 535.

18 Para el caso de la codificación en el Estado de México; véase Téllez G., Mario A., "Un proyecto de reforma de la administración de justicia en el Estado de México: las discusiones previas a la codificación (1825-1830)", Anuario Mexicano de Historia del Derecho, México, UNAM, vol. XIII, passim. Y también Cruz, Óscar, La codificación en México 1821-1917. Una aproximación, México, UNAM, 2004. 
más alternativa que seguir actuando con los libros y las formas que habían aprendido. Además, tenían que seguir juzgando, asesorando jueces legos y defendiendo a quienes acudían a sus despachos para que los representaran en los tribunales.

Hay autores contemporáneos como Francisco Tomás y Valiente que han criticado severamente al arbitrio judicial, calificándolo como una de las formas más acabadas del despotismo: revistiendo de secreto a la sentencia, a pesar de ser el acto más decisivo de la administración de justicia, "en beneficio de la libérrima actuación del juez y en detrimento de la claridad, racionalidad y legalidad del acto culminante del proceso penal". ${ }^{19}$ Por supuesto que esta opinión encuentra sus antecedentes en las fuentes de la segunda mitad del siglo XVIII y de la primera mitad del XIX que habían rechazado la continuidad del arbitrio judicial, y posiblemente en una consulta más exhaustiva de expedientes criminales. No obstante, esta perspectiva, a la luz de nuestra propia experiencia con cientos de expedientes criminales del Estado de México es, como ya lo adelantamos, distinta y coincide con otros trabajos que han visto la luz de forma reciente. Si bien reconocen la discrecionalidad de que gozaba el juez para castigar prácticamente a su criterio los delitos y los excesos que seguramente se cometieron en nombre del arbitrio judicial, por otro lado, coinciden en señalar que fue precisamente esa discrecionalidad la que sirvió para atemperar la crueldad y violencia de las penas ordinarias establecidas por la propia doctrina y legislación penal vigente hasta esos momentos.

\section{LA ADMINISTRACIÓN DE JUSTICIA CRIMINAL EN LA BAJA JUSTICIA}

Una vez establecidas algunas de las coordenadas que permiten entender al arbitrio judicial en el México del siglo XIX, nos vamos a ocupar de lo que sucedía en el foro del Estado de México. Básicamente vamos a recuperar algunos expedientes para apreciar cómo funcionó el arbitrio judicial bajo la hipótesis - que no vamos a comprobar en esta ocasión sino sólo a dar más indicios - de que esta importante institución sirvió, en general, para atemperar el rigor del derecho criminal vigente, como ya lo señalamos arriba. Por supuesto que eso no significa que la sentencia de primera instancia pudiera ser modificada en apelación o suplicación, como aquí queda demostrado. Pero tampoco, previo a la aplicación de los códigos, hemos visto nunca un

19 Tomás y Valiente, Francisco, op. cit., pp. 181 y 182. 
expediente criminal para el mismo periodo, que la modificación en alguna instancia superior fuera para aplicar la pena ordinaria.

El primer caso que recuperamos, de los muchos que hemos revisado, se refiere a un expediente iniciado en septiembre de 1815. Se tuvo noticia en Toluca del homicidio de Luisa María por parte de su esposo Juan Pablo, quien desde el inicio reconoció su culpabilidad, pero la justificó por su embriaguez. ${ }^{20}$ Este expediente criminal es muy interesante por distintas circunstancias. El proceso tardó diez años en resolverse definitivamente. Es difícil decir si fue mucho o poco tiempo, porque sumado a que la vida transcurría con mayor lentitud hay que añadirle el caos institucional que hubo en la época por el cambio de régimen y la revuelta social como principales elementos. A lo largo de esa década se declaró la Independencia del país, cayó el primer Imperio y se instituyó el sistema federal como forma de gobierno. En el ámbito jurisdiccional, la baja justicia en Toluca fue administrada por estas instituciones que se sucedieron en el tiempo: primero el corregidor y después el alcalde constitucional para la primera instancia, y la segunda por la Audiencia Real primero y por la Audiencia Territorial después. Además de otras circunstancias propias del caos administrativo que debió imperar, como en 1821, cuando el alcalde constitucional de primera elección y presidente del Ayuntamiento, "habiendo llamado las causas pendientes para la calificación del indulto extraordinario de 27 de octubre último y visto la presente [reconoció] que se hallaba traspapelada".

Por fin, el 17 de marzo de 1823:

yo el licenciado D. Juan Manual Azorrey, Alcalde primero y presidente de este ilustre Ayuntamiento [Toluca], Juez de Primera Instancia y Comisario de Guerra Sustituto Interino de esta jurisdicción [...] Fallo, atento a los méritos de la causa, que por la culpa que le resulta al indicado reo Juan Pablo declaro comprendido en la gracia de indulto concedido a los delincuentes por la Junta Provisional Gubernativa de este Imperio [27/X/1821] no más en cuanto a no sufrir la pena capital a que se había hecho acreedor y lo condeno a la extraordinaria de cinco años de servicio en las obras públicas de la capital de México. Y por esta mi sentencia definitivamente juzgando, así lo pronuncio, mando y firmo.

Unos meses después, en la Ciudad de México a 4 de junio de 1823, "los señores presidente y magistrado de la primera Sala de esta exma. Audien-

20 Archivo Histórico del Poder Judicial del Estado de México (AHPJEM), exp. 16, 41 fjs. Contra el reo Juan Pablo, del 11-09-1815 al 14-02-1824. 
cia, habiendo visto esta causa con que ha dado cuenta el relator, dijeron: que confirman la sentencia del inferior y mandaron se le devuelva la causa para su inteligencia y cumplimiento". Sin embargo, ya durante el régimen federal, el 26 de enero de 1825, la Audiencia territorial revocó la sentencia a Juan Pablo, y lo condenó a ocho años al servicio de los bajeles nacionales en Veracruz.

Al menos dos cosas quedaron claras con este caso. Que el juez de primera instancia sentenció conforme al arbitrio judicial, y que en la última instancia, situación que no era frecuente, fuera aumentada, también conforme al arbitrio. Y la otra, muy importante, es que, en el uso aparente del arbitrio, los juzgadores ya ni siquiera referían ley alguna para sustentar su sentencia, simplemente emitían la sentencia. Y es aparente, porque esta situación tiene su explicación en otro lado. En efecto, fue la vieja Real Cédula emitida por Carlos III del 23 de junio de 1768, en la que se determinó que los jueces no tenían ninguna obligación de fundamentar sus decisiones al momento de juzgar; la intención era básicamente acabar con los repetitivos, extensos y agobiantes discursos que los juzgadores habían acostumbrado incluir en sus sentencias. Esta decisión indudablemente incidió en la forma de las sentencias, y su impacto se prolongó hasta muy entrado el siglo XIX. Lo que se sabe, de acuerdo a María del Refugio González, fue que hasta 1841, durante uno de los gobiernos de Santa Anna, fue cuando se determinó por ley que todos los tribunales "están obligados a expresar la ley, canon o doctrina en que funden sus sentencias definitivas". ${ }^{21}$ Es decir, una cosa era aplicar una pena extraordinaria, en virtud del arbitrio, y otra era no referir la ley penal que se estaba infringiendo.

De regreso a nuestro caso particular, se puede decir que es cierto, el arbitrio judicial atemperó el rigor del derecho criminal en la baja justicia, pero la administración de justicia, a pesar de sus limitaciones y problemas, tenía sus mecanismos de equilibrio, de allí que en la última instancia se corrigiera lo que para esos juzgadores fue un exceso en la primera. A pesar de los grandes problemas del Estado en esos momentos, los juzgadores hicieron el esfuerzo para cumplir con su función.

En 1828, el bachiller Vicente Botello solicitó examinarse de abogado, y le pidieron, como pocas veces sucedió en las decenas de exámenes que se

21 Téllez G., Mario A., "Los exámenes de abogado en el Estado de México del siglo XIX”, Revista de Investigaciones Jurídicas, México, Escuela Libre de Derecho, núm. 34, 2010, p. 788. 
tienen de la época, que hablara sobre el ámbito criminal. ${ }^{22}$ Tenía que hacer una sinopsis de los delitos, sus principios y procedimientos, y en la parte que hablaba de las funciones del juzgador decía:

Han de proporcionarse las penas a los delitos, sin que puedan calcularse por solo el daño hecho al orden público y a los particulares; deben pues examinarse muy escrupulosamente la deliberación y conocimiento del delincuente: su edad y sexo: el mal ejemplo que ocasione el delito: los impulsos ó causas que influyen á delinquir: el tiempo, el lugar, la reincidencia, el modo ó instrumentos con que se cometió aquél: la persona del autor y del ofendido; las cuales circunstancias juntas con el daño inferido á la sociedad ó a los particulares, constituyen las verdaderas medidas y naturaleza de los crímenes.

Según estos principios se conserva la moralidad de las acciones humanas: se distinguen los delitos cometidos por culpa, de los cometidos por dolo. $^{23}$

Este discurso no era otra cosa que una visión de época de lo que se entendía por el arbitrio judicial; coincidiendo con el espíritu de lo que Víctor Tau señalaba para esta institución.

Una década después, a principios de 1838, Ramona Dominga denunció que su esposo Juan José Diego cometió incesto de primer grado con su nuera María Feliciana. ${ }^{24}$ El reo fue recluido en la cárcel y la mujer en casa del juez de paz "y para saber la verdad del hecho mandé que se tomase una

22 En 1837 se dio un cambio importante en los exámenes de abogado. Dejaron de presentarse exámenes teóricos, y sólo permanecieron los prácticos. En ley de 23 de mayo de 1837 — centralismo - se expidió una ley "Para el arreglo provisional de la administración de justicia en los tribunales y juzgados del fuero común" (Téllez G., Mario A. y López Fontes, José (comps.), La legislación mexicana de Manuel Dublán y José Ma. Lozano, El Colegio de México-Suprema Corte de Justicia de la Nación-Tribunal Superior de Justicia del Estado de México, 2004, t. III, p. 392). En ella, se estableció que el recibimiento de abogados sería con los requisitos de la ley de 28 de agosto de 1830 (Téllez G., Mario A. y López Fontes, José (comps.), La legislación mexicana..., op. cit., t. II, p. 284), la cual determinó "sobre el tiempo necesario de práctica para examinarse de abogado", que se basaba en el tiempo que debía pasar los aspirantes en las academias teórico-prácticas para titularse, y donde no la hubiera, primero se examinaría en el Colegio, y luego en la primera sala del Tribunal. Posiblemente, parte de la explicación del cambio de 1837 está en esta ley, pero no podemos aseverarlo.

23 Téllez G., Mario A., "Solicitud del Sr. Don Vicente Botello sobre examinarse de abogado", en id. y López Fontes, José, Escribanos y abogados del siglo XIX mexiquense, México, Tribunal Superior del Estado de México, 2003 (DVD).

24 AHPJEM, exp. s/n., 40 fjs. Sumaria instruida en contra del reo Juan José Diego por el incesto que en primer grado cometió con su nuera María Feliciana según adentro se expresa, del 14-05-1838 al 06-03-1839. 
sencilla declaración y luego confesó de liso en llano que su suegro ha hecho uso de ella en dos ocasiones valiéndose de la fuerza". En mayo de 1838 este juzgador decidió remitirlas, junto con los reos, al juez de primera instancia del partido.

Meses más tarde, el licenciado Agustín Calderón, como defensor de Juan José Diego expuso que

es digno de compasión, como todo hombre que impelido a los placeres del amor por el lenguaje mudo, pero elocuente e imperioso de la naturaleza se haya al lado de una mujer lasciva que a la primera insinuación abre su seno y lo recibe con gusto. En efecto señor, la libertad y conocimiento de que se quebranta la ley es lo que constituye la criminalidad de las acciones y a José Diego cuando usó de su nuera le faltaba uno y otro, porque como beodo perdió el uso de sus facultades intelectuales y sujeto sólo a las sensitivas experimentaba un vivo deseo de reproducirse y veía delante de si un objeto hacia el cual se sentía arrastrado imperiosamente, por lo cual, usando a su hija política no cometió crimen de incesto sino una simple fornicación [y en todo caso] el verdadero delincuente sería la mujer pues estando José Diego poseído de embriaguez podía con mucha facilidad librarse de su solicitante.

Por lo cual, solicitaba que su defendido fuera puesto en libertad como lo pidió al principio. Este pasaje sirve para ilustrar cómo intentó desvirtuar el abogado defensor las debilidades de su defendido, pero también para apreciar parte de la mentalidad de género dominante de la época. No obstante, las autoridades jurisdiccionales se alejaron de este criterio y sentenciaron en un sentido distinto. En Toluca, a 11 de julio de 1838, el licenciado Mariano Arizcorreta, juez de letras del partido señaló que:

habiendo visto esta causa criminal instruida de oficio por el incesto cometido entre Juan José Diego y su hija política María Feliciana, y teniendo en consideración a que ésta dio aviso a Gregoria, de que el primero la había usado carnalmente, de que fue violentada, que es menor de edad [que es india], y todo lo demás que se tuvo presente [...] FALLO: que debía de dar y doy por compurgada a María Feliciana de la culpa que le resulta; y debía de condenar y condeno a Juan José Diego a tres años de obras públicas contados desde la fecha de su prisión. Hágaseles saber a los reos y remítase esta causa con su citación al Tribunal Superior.

El 6 de marzo de 1839, la Segunda Sala del Tribunal Superior confirmó la sentencia. 
Años más tarde, en febrero de 1873, Luis Perea, Francisco Valdez (a quienes se le encontraron diversos objetos) y otras personas más, fueron acusados de robo, y el juez licenciado Antonio Inclán, juez 1o. de Letras del Distrito determinó:

que de todos estos datos se infiere rectamente haber sido Francisco Valdez quien perpetró el delito de robo en la carpintería del C. Juan Espejo y por lo mismo se ha hecho acreedor a la pena respectiva; teniendo por último presente que, en orden a los demás acusados, la causa no ministra prueba alguna de delincuencia y que el C. Juan Espejo recobró parte de los objetos que le fueron robados. Con fundamento de los arts. 47, frac 3a., 54, frac. 3a., 16 y 22 de la ley de 5 de enero de 1857, la doctrina del Dr. Gutiérrez, Pract. Crim. Tomo 1o., P. 1a. cap. 8o. no. 32, y la ley 8a. tit. 31, P. 7a. vers: "Otros[i] deben catar cual es el yerro" [...] y teniendo presente que el C. Juan Espejo recobró parte de los objetos robados, fallo: "Primero: que debía dar y [dio por compurgado] a Francisco Valdez [...] con la prisión sufrida y se le condena a pagar al C. Juan Espejo [...] los instrumentos que le faltan al precio que han fijado sus testigos y en abonos de tres ps. cada mes. Segundo: se sobresee en esta causa respecto de los demás inculpados". ${ }^{25}$

Como en otros casos de época, el juzgador de primera instancia resolvió, apoyado en el arbitrio judicial, citando otra vez la ley de Partidas correspondiente. Y aunque la ley de enero de $1857^{26}$ en las partes citadas señala el castigo que debían recibir los ladrones, en distintas modalidades, el juzgador decidió dejarlo libre por la prisión que ya había sufrido el delincuente y sobreseyó el caso.

De la misma manera que sucedió en muchos otros casos de distintos delitos a lo largo del periodo.

Finalmente, en otro expediente criminal de principios de junio de 1901, se da cuenta que Severo Pérez intentó violar a María Fidencia y ella lo lesionó al defenderse. Él argumentó que estaba borracho, pero reconoció el ataque. Ella alegó el uso de la violencia en su defensa; después ambos se perdonaron mutuamente. El 25 de junio siguiente se resolvió el expediente en primera instancia. El juez, apoyado en las consideraciones del caso y en diversas artículos - que omitimos transcribir puntualmente para no hacerla tan fatigosa- del decreto núm. 14 de 2 de mayo de 1877, del Código Penal

25 AHPJEM, exp. 25, 81 fjs. Luis Perea y socios por sospechas de robo, del 18-02-1873 al 10-10-1874.

26 "Ley general para juzgar a los ladrones, homicidas, heridores y vagos". Téllez G., Mario A. y López Fontes, José (comps.), La legislación mexicana ..., cit., t. 8. 
del Estado y del Código de Procedimientos Penales, determinó el sobreseimiento del caso:

por lo que se refiere a los atentados contra el pudor [...] en virtud de no haber méritos para continuar la averiguación por este hecho. [...] se da por compurgado al mismo Severo Pérez con la prisión sufrida del [diez y siete] del presente mes en que se le declaró formalmente preso [... a] la fecha, por la lesión que le causó a María Fidencia [...] póngase desde luego a Severo Pérez en libertad bajo una fianza de cuarenta pesos [...]. Se absuelve a María Fidencia del cargo que se le ha hecho, por las heridas que infirió a Severo Pérez; debiéndosela poner desde luego en libertad absoluta, cancelándose la fianza que tiene otorgada.

El 29 de enero de 1902, la Segunda Sala del Tribunal, en segunda suplicación, resolvió:

que para que haya delito frustrado, se requiere, además de la intención deliberada de cometerlo, que el agente ponga al efecto cuantos medios sean necesarios para llegar a consumarlo - art. 7o. CPE en el estado- La ejecución de los actos preparatorios constituye el simple conato y la doctrina de los criminalistas está de acuerdo con ese precepto del Código. El señor Pacheco, [...]. El señor Ortolán, [...]. Finalmente: el Señor Goyena [...] y, por consecuencia, faltando esos elementos constitutivos del delito frustrado, los hechos ejecutados por el inculpado quedan en la esfera de simples atentados contra el pudor, los que no pueden castigarse, por haber otorgado su perdón la ofendida; y procede, por lo mismo, la absolución del cargo [...] con fundamento de los arts. 11 del cod. pen. 383 y 399 del de proc. en mat. y 11 de Dec. núm. 14 de 2 de mayo de 1877 [...] se revoca del superior fallo suplicado, fecha siete del pasado octubre, que revocando el inferior de fecha trece de septiembre del año pasado, impuso a Severo Pérez, juzgándolo reo del delito frustrado de violación, la pena de quinientos cuarenta y siete días de prisión con abono de la sufrida; y se absuelve del cargo que se le formuló por ese delito, confirmándose así el fallo inferior ya citado. ${ }^{27}$

Los magistrados del Tribunal lanzaron un largo discurso para desviar los argumentos de una instancia anterior que había modificado el criterio de la primera, justamente para regresar a ésta. En el expediente destaca que la argumentación jurídica está sustentada principalmente en los códigos, y la

27 AHPJEM, exp. 235, 35 fjs. Contra Severo Pérez, por atentados contra el pudor y lesiones [á] María Fidencia; y contra ésta por heridas [á] aquél, del 14-06-1901 al 24-02-1902. 
doctrina referida tampoco es la excepción. Este documento muestra el final del arbitrio y del antiguo derecho. Muy probablemente habrá otros expedientes que todavía tengan algunas reminiscencias, pero es indudable que con el final de siglo se cerró una muy larga época.

\section{Comentarios finales}

Después de este breve recorrido podemos ratificar la relevancia del arbitrio judicial en el sistema jurídico mexicano del siglo XIX, particularmente, en el Estado de México, y cuyo uso se prolongó varios lustros después de la promulgación de los códigos civil, penal y de procedimientos en los años setenta; la transición no podía ser inmediata, sólo por principio había que tener el código, familiarizarse con él y comenzar a educar a las nuevas generaciones de abogados con este cuerpo legal.

Es evidente que el arbitrio judicial fue una institución fundamental en el sistema de administración de justicia. A lo largo de este complicado periodo es posible apreciar cómo la gente, a pesar de todo, seguía tratando de buscar solución a sus conflictos, seguía acudiendo a los tribunales, y los juzgadores, ya fueran legos o abogados, hacían su labor incorporando textos y autores de distinta relevancia con mayor o menor precisión para sustentar su decisión, para juzgar, sobre todo en la segunda instancia o superiores.

De igual forma, a partir de esta experiencia acumulada a lo largo de los años, tenemos la convicción de que el arbitrio judicial fue, como decía Víctor Tau y otros autores, una institución utilizada para dulcificar el derecho criminal del siglo XIX, y que en buena medida su pervivencia se debió a la imposibilidad de sustituirlo. Ese derecho forjado a lo largo de los siglos era muy severo, y buena parte de las penas ordinarias culminaban en la ejecución del reo y, por lo tanto, los jueces haciendo uso del arbitrio atemperaban el castigo imponiendo penas extraordinarias.

Por su parte, las autoridades del Estado de México, al inicio del periodo independiente, como podía esperarse, también se pronunciaron en torno al arbitrio en el mismo sentido que la mayoría de las voces de la época. Pero no podía ser de otra forma, porque además de estas voces, tenían que consolidar el concepto de la división de funciones en el sistema político de la entidad, y el arbitrio se oponía al convertir a los juzgadores en creadores e interpretadores del derecho.

Así, después de lo que hemos visto, también podemos entender el trato que le dio la literatura de la época al arbitrio judicial, la cual, desde una 
postura ideológica se justificaba porque pretendía la transformación del derecho. Sin embargo, que haya literatura contemporánea que coincide con aquélla, a la luz de lo que sabemos para el Estado de México y otras latitudes, podríamos decir, cuando menos, que le ha hecho falta investigación de archivo. Por fortuna, y en esta dirección se inscribe este texto, que han revalorado su relevancia como institución basilar y dulcificadora de la administración de justicia, no sólo en el Estado de México sino en el ámbito hispanoamericano..$^{28}$

\section{BiBLIOGRAFÍA}

Beccaria, Cesare, Tratado de los delitos y de las penas, 9a. ed., México, Porrúa, 1999 (facsimilar).

Garriga, Carlos, "Continuidad y cambio del orden jurídico", id. (coord.), Historia y Constitución. Trayectos del constitucionalismo hispano, México, Centro de Investigación y Docencia Económicas-El Colegio de México-El Colegio de Michoacán-Escuela Libre de Derecho-Grupo HicoesUniversidad Autónoma Metropolitana, 2010.

Gutiérrez, José Marcos, Práctica forense criminal, México, Imprenta de Juan R. Navarro, 1850, t. III.

LaRdizÁbal y Uribe, Manuel de, Discurso sobre las penas (1782), edición de Andrés Moreno Mengíbar, Cádiz, Universidad de Cádiz, 2001.

Memoria en que el Gobierno del Estado Libre de México, da cuenta al Congreso Constitucional, de todos los ramos que han sido a su cargo en el año

28 Véase el interesante y largo texto de Pedro Ortego que explica esa transición desde la literatura jurídica medieval y de la época moderna a la promulgación de los códigos en el siglo XIX para el caso español, y que por sus obvias influencias también podría ser explicativo para el caso hispanoamericano. En sus propias palabras: "A finales del siglo XVIII y en los albores del siglo XIX no sólo se amenazaba con el castigo a un delincuente que, en último término, no desesperaba de recibir la misericordia del rey a través de sus tribunales. En la época codificadora se amenaza con el castigo y se impone, puesto que los juzgadores, en particular los alcaldes del crimen de las Audiencias, no juzgan con arreglo a su conciencia y a una larga tradición jurídica que ampara su actuación, de manera que no caben inclinaciones a la mitigación, ni conmutaciones, ni perdones del Viernes Santo. Ahora sólo la ley, aunque contenga castigos más moderados que los previstos en la legislación de raigambre medieval o moderna. Es la propia ley, la que establece la moderación y los límites de la misma, es el legislador el que se impone frente al juez. No sólo se camina hacia una justicia de leyes y se abandona una justicia de jueces, sino que también se han legalizado aspectos cruciales del Derecho criminal del Antiguo Régimen”, Ortego, Pedro, op. cit., p. 299. 
economico, corrido desde 16 de octubre de 1829, hasta 15 de igual mes de 1830. Presentada el día 2 de marzo de 1831, s. p. i.

Ortego, Pedro, "De la literatura jurídica al código penal. Causas y circunstancias en el derecho histórico español", Boletim da Facultade de Direito de Coimbra, núm. 83, 2007.

Ramos NúÑEz, Carlos, El Código napoleónico y su recepción en América Latina, Lima, Pontificia Universidad Católica del Perú, 1997.

TAu AnzoÁtegui, Víctor, Casuismo y sistema. Indagación histórica sobre el espíritu del derecho indiano, Buenos Aires, Instituto de Investigaciones de Historia del Derecho, 1992.

TÉLlez G., Mario A., "La forma de graduar a los abogados en el Estado de México durante el siglo XIX", Revista Mexicana de Historia del Derecho, UNAM, Instituto de Investigaciones Jurídicas, vol. XXXII, julio-diciembre de 2015.

TéLlez G., Mario A., La justicia criminal en el Valle de Toluca 1800-1829, Estado de México, El Colegio Mexiquense, 2001.

TéLlez G., Mario A., "Los exámenes de abogado en el Estado de México del siglo XIX”, Revista de Investigaciones Jurídicas, México, Escuela Libre de Derecho, núm. 34, 2010.

Téllez G., Mario A. y LóPez Fontes, José (comps.), La legislación mexicana de Manuel Dublán y José Ma. Lozano, El Colegio de México-Suprema Corte de Justicia de la Nación-Tribunal Superior de Justicia del Estado de México, 2004.

TéLlez G., Mario A. y LóPez Fontes, José, Escribanos y abogados del siglo XIX mexiquense 1803-1905, México, Tribunal Superior de Justicia del Estado de México, 2003 (DVD).

TomÁs y VALIENTE, Francisco, El derecho penal de la monarquía absoluta (siglos XVI, XVII y XVIII), Madrid, Tecnos, 1992.

YANGILEVICH, Melina, "Administración de justicia, derecho, gobierno y prácticas judiciales en la construcción estatal (Buenos Aires, 1821-1886)", en CASElli, Elisa (coord.), Justicias, agentes y jurisdicciones. De la monarquía hispánica a los Estados nacionales (España y América), Madrid, FCE, 2016. 